\title{
Article
}

\section{Intimate Partner Violence and clinical coding: issues with the use of the International Classification of Disease (ICD-10) in England}

Olive, Philippa

Available at http://clok.uclan.ac.uk/23872/

Olive, Philippa ORCID: 0000-0002-9175-1285 (2018) Intimate Partner Violence and clinical coding: issues with the use of the International Classification of Disease (ICD-10) in England. Journal of Health Services Research and Policy, 23 (4). pp. 212-221. ISSN 1355-8196

It is advisable to refer to the publisher's version if you intend to cite from the work. http://dx.doi.org/10.1177/1355819618781413

For more information about UCLan's research in this area go to http://www.uclan.ac.uk/researchgroups/ and search for <name of research Group>.

For information about Research generally at UCLan please go to http://www.uclan.ac.uk/research/

All outputs in CLoK are protected by Intellectual Property Rights law, including Copyright law. Copyright, IPR and Moral Rights for the works on this site are retained by the individual authors and/or other copyright owners. Terms and conditions for use of this material are defined in the policies page. 


\title{
Intimate Partner Violence and clinical coding: issues with the use of the International Classification of Disease (ICD-10) in England
}

\begin{abstract}
Objectives

To investigate the availability of intimate partner violence (IPV) related population health information in England and the possibility of identifying IPV exposed population sample frames from administrative health data systems in England employing the International Classification of Disease (ICD).
\end{abstract}

\section{Methods}

Research design was an exploratory mixed method approach that involved trend analysis of numbers of applications of ICD IPV classifications for admissions to NHS hospitals in England over a five-year period and semi-structured focus group interviews with clinical coders at an NHS Hospital.

\section{Results}

Use of ICD IPV classifications were generally low across NHS Trusts in England. There was notable variation in the numbers of applications across NHS providers which demographic differences or rates of violence perpetration would not account for. The interview findings revealed conceptual ambiguity regarding IPV classifications which presented challenges for clinical coding and raised questions about the reliability and validity of ICD's IPV classifications.

\section{Conclusion}

It would not be possible to extract robust data about populations exposed to IPV for the purposes of audit, governance or research from health information systems 
using current ICD-10 classifications. Development of these ICD codes is essential for violence and abuse to be captured more accurately in health information systems and afforded greater prioritization and funding proportionate to the health burden and service demands that IPV is responsible for.

Keywords: International Classification of Disease; IPV; administrative health data 


\section{Introduction}

The health burden of gender-based (intimate partner and sexual) violence (hereafter, IPV) is massive and enduring, often extending beyond the immediate impact to cause long-term mental and physical health losses. ${ }^{1,2}$ The economic cost to society in terms of the health and wellbeing impact of gender-based violence, and corresponding health service costs, were estimated to be $€ 21 \mathrm{~b}$ for the UK in $2012 .{ }^{3}$ This estimate, is likely to be conservative, however, primarily because the level and quality of information about gender-based violence recorded in health systems is reportedly poor. ${ }^{2}$

The importance of good data capture cannot be overstated. Population health information produced from data recorded in health systems has a number of secondary uses: it is used to monitor health trends over time, ${ }^{4}$ identify health service utilization and demands,${ }^{5}$ develop patient care pathways,${ }^{6}$ monitor the burden of disease,,${ }^{7,8}$ inform financial and service planning, ${ }^{9}$ and produce sample frames for clinical audit, governance and research. ${ }^{10,11}$ Inconsistent data capture means that administrative health data, estimations of impact, priority, service needs and subsequent commissioning decisions are likely distorted and prejudicial.

The production of good quality health information for secondary uses is reliant on accurate documentation of events and information by practitioners at the point of care and encoding of that information through sound classification systems. As such, there are three potential sites where data capture error may be introduced. The first site is the patient-provider interface, which is dependent upon patient report and practitioner acknowledgment of violence during the clinical encounter. Second, is the providermedical record interface, which is reliant upon practitioner documentation in the medical record of the patient reporting of IPV as a causative factor of the person's 
health problem(s). The third potential site is the medical record-clinical coderclassification system interface, when medical record data is coded.

This third site is the primary focus for this paper. Coding is 'the process whereby information written in the patient notes is translated into coded data and entered onto hospital information systems,${ }^{4}$ In acute care hospitals in England, this translation and coding is done by teams of professionalised clinical coders. ${ }^{12}$ This paper reports on a feasibility study that assessed the possibility of identifying IPV population sample frames from administrative health data systems in England employing the International Classification of Disease and Health Related Problems ( (ICD) coding system. This study has global relevance as the ICD classification tool is employed by more than 100 countries to produce population health data. ${ }^{13}$

\section{Administrative health data}

There are three main levels of administrative health data. The first level is the patient medical record created at the point of care and which holds most detail about an individual's health problems, diagnostics and management plans. First-level health data is recorded in real time by different actors, at different locations, for different health service systems. ${ }^{14}$ Second- and third-level administrative data is less detailed, as selected information is encoded using classification systems in response to local (second level) and national/international (third level) data collection requirements mandated by government and partner organisations. In England, as in many countries, the ICD is the main classificatory tool for coding episodes of care in hospitals. The ICD forms part of the World Health Organization Family of International Classifications (WHO-FIC), an internationally endorsed classification scheme for measuring, in standardized ways, health burdens within and between populations over time to inform global and local 
public health priorities and programmes. ${ }^{15}$ The ICD undergoes review and revision periodically and a new version (ICD-11) is anticipated later in 2018. The current version in operation, ICD-10, holds over 14,000 classifications, each with its own unique, four-character, alphanumeric code.

\section{ICD-10 and the classification of violence}

The definition of IPV includes multiple types of violence (physical, sexual, psychological or controlling behaviours). ${ }^{16}$ An overview of the ICD-10 classifications most closely aligned with these different types of IPV, along with their ICD conceptual framing and additional defining characteristics, is presented in Table 1.

Table 1. Characteristics of ICD-10 classifications for forms of violence.

\begin{tabular}{|c|c|c|c|c|c|}
\hline $\begin{array}{l}\text { ICD } \\
\text { Code }\end{array}$ & Type of Violence & Conceptual Frame & $\begin{array}{l}\text { By V-P* } \\
\text { Relation }\end{array}$ & $\begin{array}{l}\text { By } \\
\text { Location }\end{array}$ & $\begin{array}{l}\text { Frequency } \\
\text { of violence }\end{array}$ \\
\hline T74.0 & Neglect or abandonment & Maltreatment & No & & Not specified \\
\hline $\mathrm{T} 74.1$ & $\begin{array}{l}\text { Physical Abuse } \\
\text { (inc child abuse) }\end{array}$ & Maltreatment syndrome & Spouse & & $\begin{array}{l}\text { Implies } \\
\text { repeat acts }\end{array}$ \\
\hline T74.2 & Sexual Abuse & Maltreatment & No & & Not specified \\
\hline T74.3 & Psychological abuse & Maltreatment & No & & Not specified \\
\hline $\mathrm{T} 74.8$ & Other mixed forms & Maltreatment & No & & Not specified \\
\hline T74.9 & Unspecified & Maltreatment & No & & Not specified \\
\hline X85-Y09 & Assault by objects/entity & Assault & No & Yes & Not specified \\
\hline Y05 & Sexual assault (bodily force) & Sexual assault & No & Yes & Not specified \\
\hline Y06.0 & Neglect and abandonment & $\begin{array}{l}\text { Assault, neglect, } \\
\text { abandonment }\end{array}$ & $\begin{array}{l}\text { Limited } \\
\text { range }\end{array}$ & & Not specified \\
\hline Y07.0 & $\begin{array}{l}\text { Mental cruelty, physical } \\
\text { abuse, sexual abuse, torture }\end{array}$ & Assault, maltreatment & $\begin{array}{l}\text { Limited } \\
\text { range }\end{array}$ & & Not specified \\
\hline Z63.0 & $\begin{array}{l}\text { Persisting control, hostility, } \\
\text { criticism, physical violence }\end{array}$ & $\begin{array}{l}\text { Problems relating to } \\
\text { primary support group }\end{array}$ & Partner & & $\begin{array}{l}\text { Repeat acts } \\
\text { over time }\end{array}$ \\
\hline
\end{tabular}

*victim-perpetrator

ICD-10 arranges these classifications into one of three conceptually discrete, larger categories:

\footnotetext{
T74 Maltreatment syndromes

- $\quad$ X and Y Assault

- $\quad$ Z63 Problems relating to primary support group
} 


\section{T74 Maltreatment syndromes}

In this category, the fourth character denotes a specific form of maltreatment. T74.1 is the code for 'Physical abuse', which includes 'battered spouse' and 'battered baby or child'. It is the only code in this category that specifies a person's partner as perpetrator, but the term 'spouse' may limit its use in cases of violence in non-marital intimate relationships. The inclusion of 'battered baby or child' in this category means that the code T74.1 cannot be assumed to refer to IPV. Even if disaggregated by age the classification may have been applied for adults receiving services in relation to their maltreatment when a child.

\section{$X$ and Y Assault (external cause codes)}

$\mathrm{X}$ and $\mathrm{Y}(\mathrm{X} 85 \rightarrow \mathrm{Y} 09)$ assault codes are differentiated by the cause of injury, for example 'sharp object' (X99), ‘drowning' (X92) and 'bodily force' (Y04). A fourth character option for assault codes is 'location' - the type of place where the assault occurred. There are no victim-perpetrator relationship options for the main assault classifications, with the exception of categories 'Y06 neglect and abandonment' and 'Y07 other maltreatment'. For these categories, use of the fourth character '. 0 ' designates a spouse or partner as perpetrator. The definition for Y07 includes mental cruelty, physical abuse and sexual abuse. By including these multiple forms of violence and specifying spouse or partner as perpetrator, Y07.0 aligns with WHO's ${ }^{16}$ definition of IPV.

Intimate partner sexual violence. There is one ICD classification for sexual assault, 'sexual assault by bodily force' (Y05). Sexual assault, as with most other assault categories, is sub-classified only by place of occurrence and not by victim-perpetrator relationship. So, whilst 'Y05 sexual assault' as an overall category may be captured by 
ICD-10, important information about the victim-perpetrator relationship is not.

Furthermore, framed in terms of 'bodily force', this classification potentially excludes sexual violence and rape in the absence of physical force.

\section{Z63 problems relating to primary support group}

$\mathrm{Z}$ codes represent factors that influence a person's health state and Z63.0 'problems in relationship with spouse or partner' is defined as: 'discord between partners resulting in severe or prolonged loss of control, in generalization of hostile or critical feelings or in a persisting atmosphere of severe interpersonal violence (hitting or striking) ${ }^{17}$ This classification, which captures subjection to multiple forms of violence, has relevance for IPV. However, defined as a pattern of behaviours and severe acts of violence over time, Z63.0 may exclude single incidents and 'non-severe' violence.

ICD-10 classifications: consistency and reliability

The ICD-10 classifications that most closely align with the $\mathrm{WHO}^{16}$ definition of IPV are T74.1 maltreatment (physical abuse) by spouse, Y07.0 other maltreatment by partner and Z63.0 problems in relationship with partner. However, there is a notable inconsistency across ICD-10 classifications in the way that forms of violence are specified: some are specified by a limited set of victim-perpetrator relationships (Y06; Y07; T74.1); some by place of occurrence (X85 - Y09); and some provide no further distinction beyond a broad conceptualization of a form of violence (T74.2; T74.3; T74.8; T74.9). Previous research has found that ambiguity in classification categories, issues with the biomedical orientation, and perceived stigmatizing or distress-causing potential of codes affect how codes are applied. ${ }^{18,19}$ Nevertheless, ICD codes for IPV 
have been used to identify IPV-exposed population sample frames in the United States. ${ }^{10,11}$

With three IPV classification options (T74.1, Y07.0 or Z63.0) that could be used to code an episode of health care as IPV related, this feasibility study aimed to establish whether the ICD-10 classification system could deliver population health data and reasonably robust IPV sampling frames for audit, governance or research purposes. The questions that this study addressed were:

- How many admitted episodes of care in hospitals in England were encoded with T74.1, Y07.0 or Z63.0?

- What were the qualitative differences between these three classifications?

- Across which ICD-10 classifications were episodes of care for IPV related health problems distributed?

\section{Methods}

The study design was a descriptive and exploratory multi-method approach that involved:

- Trend analysis of numbers of applications of ICD-10 classifications (T74.1; Y07.0; Z63.0) to admissions to NHS hospitals in England over five years.

- Semi-structured focus group interviews with clinical coders at an NHS hospital in England to obtain their qualitative accounts of classifying and coding episodes of care with classifications for IPV from ICD-10. 


\section{Trend analysis of applications of ICD-10 codes T74.1, Y07.0 and Z63.0}

A request was made to the North West Public Health Observatory (UK) for the numbers of people aged sixteen years or older admitted to hospital in England between 2006/07 to 2010/11, whose admission was coded with ICD-10 code T74.1, Y07.0 or Z63.0, disaggregated by sex and NHS Trust. Data were received as frequencies of applications in excel spreadsheets.

\section{Semi-structured focus group interviews with clinical coders}

Six clinical coders from an NHS Trust in England took part in two focus group interviews. The focus group interviews were semi-structured. Participants were asked about qualitative differences between the three IPV related classifications and how they would decide which code to apply. This led to participants describing their experiences in practice of coding episodes of care in which IPV was a causative factor in health problems. The focus group interviews took place in February and May 2012. An interview protocol attended to participants' rights, comfort, safety and well-being. Participants were aware they could stop and retract their participation at any time until the final research report was written. Each interview lasted approximately 50 minutes. Discussions were closed once the topics of an interview guide had been addressed and participants expressed they had nothing further to add. Interviews were audio-taped, transcribed, anonymized and entered into NVivo9 computer-based software programme. A realist qualitative data analysis coding framework was developed. ${ }^{20}$ After familiarization, respondents' qualitative accounts were thematically analysed for what constituted IPV (commonly referred to as 'domestic violence' by participants) and for explanatory accounts, mechanisms and reasoning that lay behind coding practices. Themed sub-sections were further analysed for patterns, connections and dissonances to produce findings that held substantive meaning. 


\section{Ethical considerations}

Consultation with public and professional stakeholder representatives shaped the research design. Ethical considerations were addressed in a research protocol and the study received favourable opinion from the Social Care Research Ethics Committee and permission to undertake the research onsite at an NHS Trust was granted.

\section{Results}

Findings from the trend analysis of applications of ICD-10 codes are presented first, followed by those from the focus group interviews. Alphanumeric codes (e.g. CCFG1, CCFG2 etc.) were used to distinguish between clinical coder respondents.

\section{Applications of ICD-10 codes T74.1, Y07.0 and Z63.0}

In the five-year period from $2006 / 07-2010 / 11$ a total of 18,056 patient (aged $\geq$ sixteen years of age) admissions in England were classified with codes T74.1, Y07.0 or Z63.0, though most $(86 \%, \mathrm{n}=15,438)$ were for Z63.0 (Figure 1). The number of applications increased annually for each code. 
Figure 1. Applications of ICD-10 codes T74.1, Y07.0 and Z63.0 for male and female patients aged $\geq$ sixteen years admitted to hospital in England from 2006/07-2010/11*
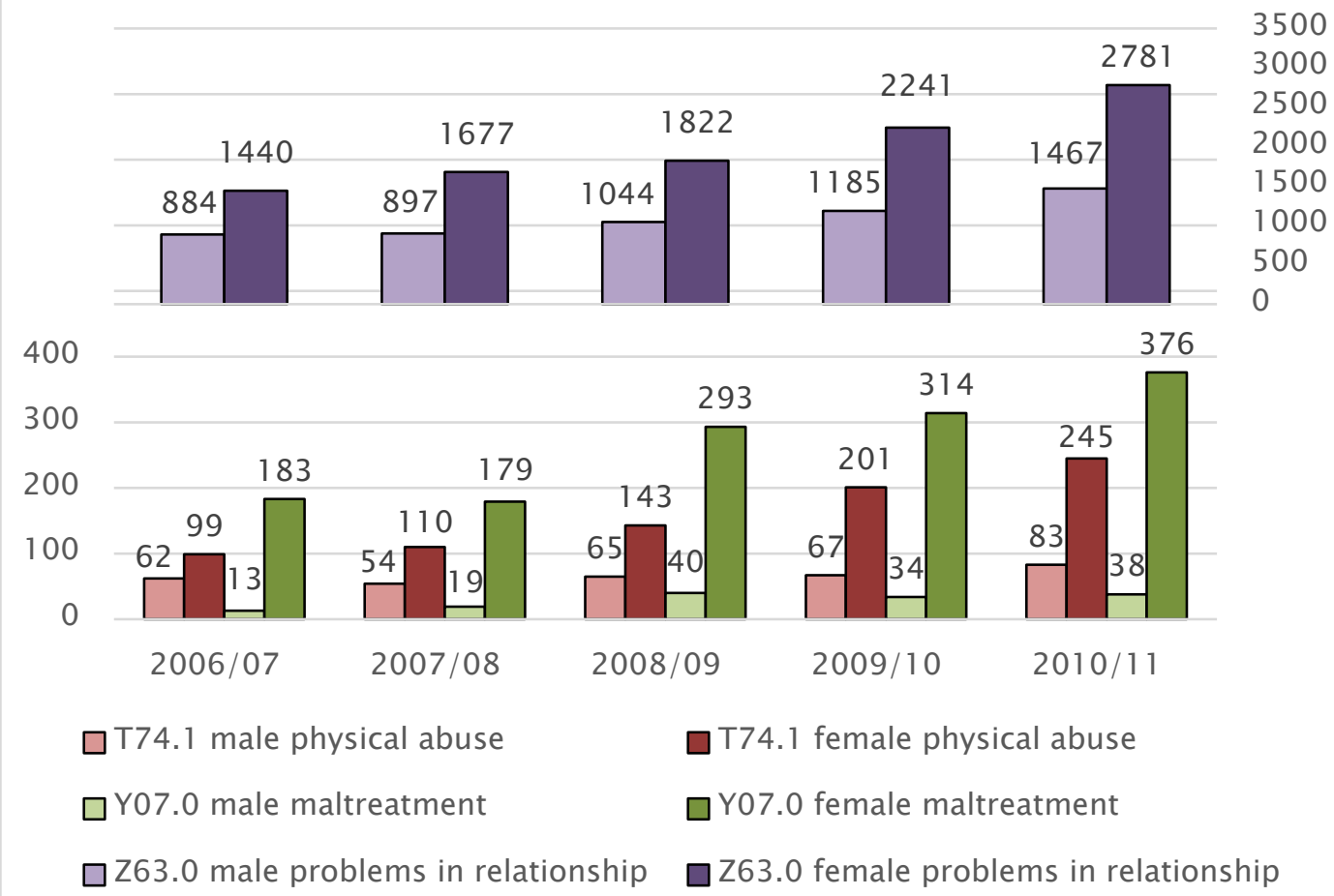

* Data presented in panel graph because of differences in numbers of applications between T74.1 / Y07.0 and Z63.0 codes.

The use of T74.1 ranged from 54-83 for men and 99-245 for women. The range of applications of Y07.0 was 13-40 for men and 183-376 for women. Z63.0 applications ranged between 884-1467 for men and 1440-2781 for women. Women's admissions were consistently more frequently classified with ICD-10 codes T74.1, Y07.0 or Z63.0 than admissions for men, though this was most noticeable for code Y07.0. The proportion of T74.1 applications per annum for women were $62 \% ; 67 \%$; $63 \% ; 75 \% ; 75 \%$ respectively (mean 68\%, median 67\%). The proportion of applications of Z63.0 were similarly greater for women's admissions: $62 \% ; 65 \% ; 64 \% ; 65 \% ; 66 \%$ per annum respectively (mean 64\%, median 65\%). For Y07.0, the proportion of applications each year for female patients was 93\%; 90\%; 88\%; 90\%; 91\% (mean 90\%, median 90\%). 


\section{Variations across service providers}

From 2006-2011, 249 NHS Trusts in England applied one or more of these ICD-10 codes to a person's hospital admission.

Figure 2. Range of number of ICD-10 code applications across NHS service providers in England, 2006 - 2011.

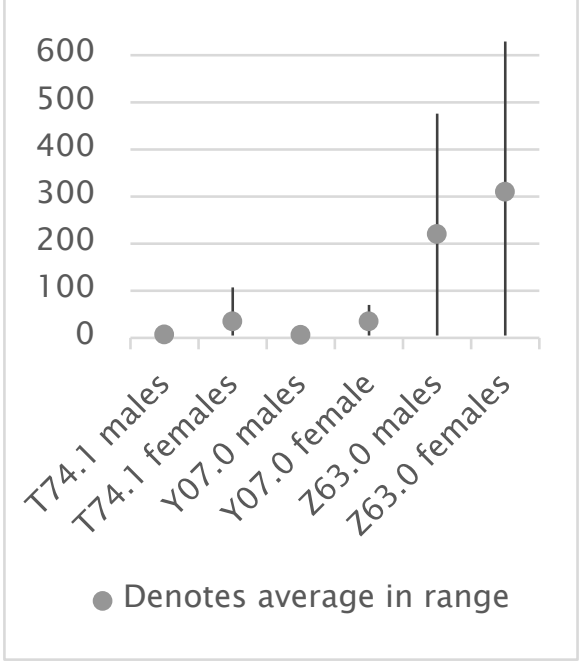

Over the five-year period, code applications across NHS service providers (Figure 2) in England ranged from:

- T74.1: < 6 to 14 for male patients and < 6 to 107 for female patients.

- Y07.0: $<6$ to 9 for male patients and $<6$ to 70 for female patients.

- Z63.0: < 6 to 476 for male patients and < 6 to 629 for female patients.

These findings illustrate notable variation in frequencies of applications across codes and between NHS Trusts. 


\section{Qualitative differences and distinctions between codes}

The clinical coder focus group interviews produced three main themes on the qualitative differences between the ICD classifications used for coding episodes of care involving IPV:

- Ambiguity over the classificatory thresholds for IPV

- Inconsistences in coding decisions in practice

- (Un)Certainty at the record-coder-ICD interface.

\section{Classificatory threshold for IPV}

In the following data extract, a coder was talking about code T74.1 (physical abuse by spouse).

If you're hit by somebody, just because it's your husband, is it domestic violence or is it not? I'm not sure now. The one that I did I think the police were involved and she didn't go back home and he were taken away so I presumed it was, I suppose and maybe I shouldn't have done. (CCFG2)

For this coder, pieces of information beyond the violence, for example, 'involvement of the police', 'leaving home', and 'police took the partner away' were heuristic anchors from a previous coding experience to justify classifying and coding an episode of care as IPV. Her account suggests that not all assaults perpetrated by one's partner constitute 'IPV.' This definitional uncertainty continued to be apparent in a discussion about severe, potentially life-threatening violence with a weapon:

It's like, if they came in and they've been stabbed by their partner, is that? It could just be a one-off argument, couldn't it? Is that still classed as a T74?

\section{(CCFG2)}

This coder's uncertainty as to whether severe violence by a partner should be classified as IPV indicates the sociocultural complexity surrounding the use of this term. Other 
respondents (CCFG3; CCFG4) expressed similar uncertainty about classifying some incidents of partner violence. For some coders, the problem centred on whether 'oneoff' incidents of partner violence were sufficient for applying the classification, or whether repeated incidents of violence were necessary. One coder clearly rejected the idea that 'one-off' incidents should be excluded:

Well yeah, it would be, because, like, you know, you could've both been out, you're really drunk, come home, had a big argument, but they may never have laid a finger on you ever before so... and he may never, ever again, so it's that one incident. (CCFG1, emphasis added)

\section{Coding decisions in practice}

The following extract begins by specifiying that generic assault and injury codes would normally be used to code incidents of interpersonal violence.

Well, if somebody's got a fractured cheekbone or whatever because they've been assaulted, you'd just code the injury and the assault, but if she said she'd been assaulted by the husband and it was proved that he had done it then is that domestic... would that make it a maltreatment syndrome, you know to use the $T$ code or is it still just an assault? I don't understand that now I've thought about it. (CCFG2)

In explaining code applications in practice, this coder expresses a qualitative distinction between the meanings behind assault codes $(\mathrm{X} 85 \rightarrow$ Y09) and maltreatment codes (T74s and Y07s). However, the organising rubric of 'maltreatment' was a difficult conceptual construct for coders in practice, as further indicated in the next extract. 
What's the difference, though, between if somebody comes in and they've been hit by somebody and they say assault but then if they say, "My partner did it," does that make it maltreatment or is it just assault? (CCFG5)

In discussing differences between the maltreatment and assault codes a debate ensued about whether the actual word 'maltreatment' would need to be documented in the health record for the maltreatment codes (Y07.0, T74.1) to be applied. The following is from this conversation:

“you can only trail maltreatment to use Y07 which we'll never use." (CCFG2)

"What's 'assault by' mean then?" (CCFG1)

"if I was to use that [Y07]. It would have to state 'maltreatment' within the case notes, otherwise I'd go for Y04 (CCFG2) [yeah I think so (CCFG3)]."

For three respondents, the classification 'Y07.0 maltreatment by partner' would only be applied if the word 'maltreatment' had been documented in the person's medical record. This was due to a coding practice called 'trailing', as mentioned above. Trailing was explained by respondents as the process of looking up words documented in medical records in ICD-10's alphabetical index to find out which code to apply. Trailing as described here means that in situations of partner violence where the term 'maltreatment' was not documented, episodes of care relating to IPV would be specified by the classification 'Y04 assault by bodily force.' In such cases, the victim-perpetrator relationship would not be captured in second or third level health information.

The claim that 'assault by partner' was sufficient to apply the code Y07.0 was made by coder CCFG1 on the grounds that physical abuse was included in the definitional explanation provided in the ICD-10: 
“It says includes physical abuse, doesn't it, Y.07. That's why I would... No, I think I'm right." (CCFG1)

Though again its application was disputed:

"if it said assault by partner...I would just trail assault." (CCFG5)

This conversation has identified coding inconsistency for 'assault by partner' amongst this team: some would classify this as Y07.0 and others as Y04. Furthermore, framing violence in terms of maltreatment is problematic, as coders in this study (CCFG1, CCFG2, CCFG4) could not recall ever having seen the word 'maltreatment' documented in patient records. This finding reveals a cultural disconnect between words written in medical records by practitioners at this NHS Trust to describe an incident of physical partner violence and the language (maltreatment) of ICD-10 that likely limits use of these codes. The practice of 'trailing' likely sustains this disconnect as coder interpretation of written records is constrained and clinicians may not be aware of the expectation to leave 'trails' in their notes.

Respondents voiced additional reservations about applying code T74.1.

with the T74s... we're a bit careful, .... It's got to be, like, a hundred per cent sure before we would put the T code on. I think we've more a tendency to code the injuries and then the $Y$ [Y07.0] code. (CCFG1)

Differences in the treatment of the T74 classification were explained in relation to ICD's primary and secondary diagnosis codes. Y07.0 denotes a secondary, external cause, a classification for primary physical injury diagnoses, whereas T74.1 denotes a primary diagnosis, a 'syndrome' in its own right, adding further complexity about what would constitute an endogenous maltreatment syndrome. 
(Un)Certainty at the record-coder-ICD Interface

Uncertainty about definitional boundaries of codes and the conditions under which they should be applied disrupted these respondents' ideas of classification certainty engendered through objective ICD coding practices. Respondent CCFG2 was troubled by her earlier self-revelation of coding based on presumption and interpretation of the health record rather than words categorically recorded. Coders frequently referred to the importance of documentation in relation to coding practices, describing this as an essential component of the ICD classification system:

“...if we haven't got that information documented [partner perpetrated violence] then we can only use the Y04 [non-specific assault code]. So some of the Y04s could actually be domestic violence." (CCFG1)

Certainty and confidence in coding were rooted in the premise that classifications represented precisely what was documented in the health record. However, distinctions between classifications of assault and maltreatment were contested by respondents in this study. In summing up, respondents agreed that although there may be varied interpretations, differences were mediated through team consensus.

"we tend to have conversations about these things within the office to try and come up with the right coding." (CCFG4).

Coders in this study indicated that Z63.0 was mostly used for classifying admissions for self-harm, such as drug overdoses, in response to mental health practitioners documenting that problems with partner relationships were a contributing factor to the patient's state of mind, leading to self-harm. Examples of the wording in the notes that would lead to coding an admission as Z63.0 were: 'overdose, argument with husband', 'argument with girlfriend' 'marital problems', 'disharmony' (CCFG1). 
This wording clearly connects with the first part of Z63.0's definition: 'Problems in relationship with spouse or partner'. However these descriptors do not fulfil the second sentence of Z63.0's definition which refers to a hostile environment and severe violence. Such usage of the Z63.0 classification means that its validity as a category for IPV in administrative health data is doubtful.

\section{Discussion}

Though increasing over time, usage of the three codes found in this study appears low given what is known about the incidence, prevalence and health impacts of IPV.

Variance in the number of applications across NHS providers was not likely attributable to differences in rates of IPV victimization as regional variations of victimisation are not statistically significant. ${ }^{21}$ Application variance may be explained in part by differences in the size of hospital populations although the range of variation, from less than six for all codes to hundreds, suggests other factors at play. The qualitative data findings indicate that variance was more likely connected to local recording and coding practices.

Code applications were found to be sensitive to discourses of what qualifies as IPV. Some coders in this study were unsure whether a 'one-off' incident constituted 'IPV'. This uncertainty reflects the findings of a study carried out amongst nurses and doctors in an emergency department in England, where multiple classifications were used during consultations. ${ }^{14}$ Previous research similarly found that coding was more difficult when code meanings were unclear and when health problems did not fit within a biomedical model. ${ }^{18}$ The status of intimate partner violence as a non-biomedical cause of health problems also likely contributes to lower than expected code applications. 
This study found a vocabulary disconnect between the words written by health practitioners in medical records to document intimate partner physical violence (hit; assault; stabbed) and the vocabulary of ICD-10 (maltreatment). This meant that, following coding trailing practices, an episode of health care for injuries sustained through an assault by a partner may not be classified with an IPV code because it was not documented as 'maltreatment' in the medical records. Instead, such episodes of care would be distributed across assault codes with no record of victim-perpetrator relationship. Though more widely used in the US and in Safeguarding Children policy documents, ${ }^{22,23}$ the term maltreatment pertaining to acts of harm against adults is seldom used in the UK, rather violence, abuse, exploitation and neglect are more common. ${ }^{24,25}$ That said, applications of child maltreatment codes were also found to be notably lower than expected indicating that there may be some reluctance amongst general practitioners in England to use maltreatment codes despite a common policy and code vocabulary. ${ }^{19}$

IPV continues to have some degree of social stigma attached to it and it may also be that terms such as maltreatment, abuse, intimate partner or domestic violence are perceived as more stigmatizing than the descriptors of an act of violence (e.g. punched, dragged, pushed) and victim-perpetrator relationship (e.g. partner, ex-partner) commonly reported by patients to health practitioners. ${ }^{26}$ Coders in primary care were reluctant to use a code if it was perceived as stigmatizing or had the potential to cause patient distress if the person saw it. ${ }^{18}$ In this study, coders assigned assault codes with relative ease in comparison to the uncertainty apparent when constructs such as intimate partner or domestic violence and maltreatment were invoked. Despite best efforts, 
coding is not objective and neutral. Practitioners and coders in this and previous research were sensitive to potential meanings and implications of abuse-related code applications, whilst generic assault codes provide coding options that are perceived as safer or less risky.

In the face of uncertainty, clinical coders in this study made decisions about which codes to apply by discussion and consensus agreement. In this way coders aim to reproduce certainty and confidence in ICD codes. Yet such consensus methods also likely reproduce local coding traditions and sociocultural beliefs. Understood as a community of practice, teams of clinical coders will influence which codes are applied locally and this likely explains variation in the use of codes Y07.0, T74.1 and Z63.0 across NHS Trusts in England.

Of the three codes (Y07.0, T74.1, Z63.0) representing a person's health need arising from IPV, Y07.0 was seemingly most relevant because of its 'external cause' status. T74.1's status as a primary (endogenous) diagnosis meant it was less likely to be applied in practice. Z63.0's use for general problems in intimate relations not necessarily arising from IPV means that this classification likely captures a broader population. Overall, codes Y07.0 and T74.1 likely lack sensitivity, and Z63.0 lacks specificity, as IPV-related population health measures and sampling frames.

The findings of this study raise questions about the reliability and validity of ICD-10 IPV codes, posing challenges for secondary data users. Concepts such as IPV, domestic violence and maltreatment introduce ambiguity because their definitional boundaries, classificatory thresholds and meanings vary across time and place. ${ }^{27}$ The 
importance of language cannot be overstated. ${ }^{28}$ A simpler taxonomy of violence that does not require threshold interpretation or judgement and which is transferable across time and place even in contexts where partner violence is normative is needed. Recent developments in IPV measurement recommend such a transition..$^{28,30}$

New criteria for partner physical abuse, partner psychological abuse, partner sexual abuse and partner neglect classification have been developed, successfully field tested and adopted into the Diagnostic and Statistical Manual of Mental Disorders $(\mathrm{DSM}-\mathrm{V}) .{ }^{28}$ The resultant criteria condense classification thresholds to three items: an act of abuse/neglect, any actual or potential for more than inconsequential impact and partner relationship between person and perpetrator. These new criteria have been proposed for inclusion in ICD-11, though specific ICD-11 field testing has yet to be published. ${ }^{29}$ Good practice would be for victim-survivors of IPV to be included in stakeholder consultations for ICD code development as practitioners' fears about the potential stigmatizing impact for patients may not actually be warranted. ${ }^{18}$ Development of a coherent taxonomy for violence classification is clearly needed for the production of more accurate and reliable IPV incidence, prevalence and health impact data across time and place. ${ }^{30}$

For policy makers and commissioners, this research identifies the likelihood of substantial undercount of IPV as a cause of health problems in administrative health data, highlighting a hugely important shortfall in our population health knowledge. Until such time that reliable IPV taxonomies, data recording at the point of care, and classification in administrative health data systems are developed and implemented, national victimisation surveys, such as the Crime Survey of England and Wales, may be 
better sources of estimates of health impact and health service utilization, though these too are limited.

\section{Conclusion}

Presently IPV administrative health data is partial and fragmented, distributed across unreliable and non-specific codes. It would not be possible to robustly extract data about populations exposed to IPV for the purposes of audit, governance or research from health information systems using current ICD-10 classifications. These findings mean that health consequences and service utilization and demands due to IPV are not being recorded and measured in health information systems that encode health data through ICD-10. This is not good for the health economy as policy makers and commissioners of health services rely on robust administrative health data to set public health priorities, monitor effectiveness of programme interventions and to commission and fund services. Practitioners, most commonly nurses, report additional, resourceintensive work associated with patient report of IPV. With better data capture it may be possible to make the case for an IPV commissioning premium so that the workforce is adequately resourced to respond and intervene effectively. Development of ICD codes is essential for violence and abuse to be more accurately captured in health information systems and afforded greater prioritization and funding proportionate to the health burden and service demands it is responsible for. 


\section{References}

1. Black MC, Basile KC, Breiding MJ, et al. The National Intimate Partner and Sexual Violence Survey. Atlanta, Georgia: National Center for Injury Prevention and Control, http://www.cdc.gov/ViolencePrevention/pdf/NISVS_Report2010-a.pdf (2011, accessed 29 August 2017).

2. World Health Organisation. Global and regional estimates of violence against women: prevalence and health effects of IPV and non-partner sexual violence. Geneva: World Health Organization, http://apps.who.int/iris/bitstream/10665/85239/1/9789241564625_eng.pdf (2013, accessed 29 August 2017).

3. Walby S and Olive P. Estimating the Costs of Gender-Based Violence in the European Union. Vilnius: European Institute for Gender Equality, http://eige.europa.eu/content/document/estimating-the-costs-of-gender-basedviolence-in-the-european-union-report (2014, accessed 29 August 2017).

4. Royal College of Physicians. Top ten tips for coding - a guide for clinical staff. London, Royal College of Physicians Health Informatics Unit, https://www.rcplondon.ac.uk/projects/outputs/top-ten-tips-coding-guide-clinicalstaff (2007, accessed 29 August 2017).

5. Moghaddasi H, Rabiei R, and Sadeghi, N. Improving the quality of clinical coding: a comprehensive audit model. Journal of Health Management and Informatics, 2014; 1: 36-40.

6. Mirza, S. An Introduction to clinical coding. Health Service Journal Online, https://www.hsj.co.uk/topics/technology-and-innovation/an-introduction-to-clinicalcoding/5052917.article (2013, accessed 29 August 2017).

7. Bajaj Y, Crabtree $\mathbf{J}$ and Tucker AG. Clinical coding: how accurately is it done? Clinical Governance: An International Journal 2007; 12: 159-169.

8. Murray CJL, Ezzatti M, Flaxman AD, et al. GBD 2010: design, definitions, and metrics (Supplementary appendix). The Lancet 2012; 380: S1-140.

9. Thavarajah D, Francis T, Rees L, et al. Clinical coding: are trusts being shortchanged? British Journal of Healthcare Management 2010; 16: 26-32.

10. Btoush R, Campbell JC and Gebbie KM. Care provided in visits coded for IPV in a national survey of emergency departments. Women's Health Issues 2009; 19: 253262.

11. Rhodes KV, Kothari CL, Dichter M, et al. Intimate partner violence identification and response: time for a change in strategy. Journal of General Internal Medicine 2011; 26: 894-899.

12. Taylor P. From patient data to medical knowledge: the principles and practice of health informatics. Oxford: Blackwell, 2006.

13. World Health Organization International Classification of Diseases Information Sheet, http://www.who.int/classifications/icd/factsheet/en/ (2017, accessed 29 August 2017).

14. Olive P. Classificatory multiplicity: IPV diagnosis in emergency department consultations. Journal of Clinical Nursing 2017, 26: 2229-2243.

15. Madden R, Sykes C and Ustun TB. World Health Organization Family of International Classifications: definition, scope and purpose, http://www.who.int/classifications/en/FamilyDocument2007.pdf (2007, accessed 29 August 2017). 
16. World Health Organisation. Violence against Women: Intimate partner and sexual violence against women, http://www.who.int/mediacentre/factsheets/fs239/en/ 2012, accessed 29 August 2017).

17. World Health Organization. International Classification of Diseases, http://www.who.int/classifications/icd/en/ (2016, accessed 29 August 2017).

18. De Lusignan S, Wells SE, Hague NJ, et al. Managers see the problems associated with coding clinical data as a technical issue whilst clinicians also see cultural barriers. Methods of Information in Medicine 2003; 42: 416-422.

19. McGovern A, Woodman J, Allister J, et al. A simple clinical coding strategy to improve recording of child maltreatment concerns: an audit study. Journal of Innovation in Health Informatics 2015; 22: 227-234.

20. Miles MB and Huberman AM. Qualitative Data Analysis. California: Sage, 1994.

21. Walby S and Allen J. Domestic violence, sexual assault and stalking: Findings from the British Crime Survey. London: Home Office Research, Development and Statistics Directorate, http://eprints.lancs.ac.uk/3515/1/Domesticviolencefindings_2004_5BritishCrimeSur vey276.pdf (2004, accessed 29 August 2017).

22. Montana S and Hernandez LM. Adult Maltreatment and Adult Protective Services in Central California. Central California Social Welfare Evaluation, Research and Training Center, http://calswec.berkeley.edu/files/rtn-reportfiles/adultmaltreatment.pdf (2008, accessed 29 August 2017).

23. Department for Education. Working together to safeguard children: A guide to interagency working to safeguard and promote the welfare of children. Department for Education, https://www.gov.uk/government/publications/working-together-tosafeguard-children--2 (2017, accessed 29 August 2017).

24. National Institute for Health and Care Excellence Domestic violence and abuse, https://www.nice.org.uk/guidance/qs116 (2016, accessed 29 August 2017).

25. NHS England. Safeguarding, https://www.england.nhs.uk/ourwork/safeguarding/ (2017, accessed 29 August 2017).

26. Olive P. First Contact: Acute stress reactions and experiences of emergency department consultations following an incident of IPV. Journal of Clinical Nursing 2017; 26: 2317-2327.

27. Pallitto C and Garcia-Moreno C. Ch.2 IPV and Its Measurement: Global Considerations in Foran HM, Beach SRH, Smith Slep AM, et al. (Eds), Family Problems and Family Violence: Reliable Assessment and the ICD-11. New York: Springer Publishing, 2013.

28. Heyman RE, Smith Slep AM and Foran, HM. Enhanced Definitions of IPV for DSM-5 and ICD-11 May Promote Improved Screening and Treatment. Family Process 2015; 54: 64-81.

29. World Health Organisation. ICD-11 Revision. Geneva: World Health Organization, http://www.who.int/classifications/icd/revision/en/ (2018, accessed 27 February 2018).

30. Walby S, Towers J, Balderston S, et al., The concept and measurement of violence against women and men. Bristol: Policy Press, 2017. 